\title{
Synthesis of Graphene from Dry Ice in Flames and Its \\ Application in Supercapacitors
}

\author{
Juan Zhang ${ }^{\mathrm{a}, \mathrm{b}}$, Tian Tian ${ }^{\mathrm{a}}$, Youhu Chen ${ }^{\mathrm{a}}$, Yufang Niu ${ }^{\mathrm{a}}$, Jie Tang ${ }^{\mathrm{c}}$, Lu-Chang Qin ${ }^{\mathrm{a}, \mathrm{d}, *}$ \\ ${ }^{a}$ Division of Functional Materials and Nano-Devices, Ningbo Institute of Materials \\ Technology and Engineering, Chinese Academy of Sciences, Ningbo 315201, China \\ ${ }^{b}$ School of Materials Science and Chemical Engineering, Ningbo University, Ningbo \\ 315201, China \\ ${ }^{c}$ National Institute for Materials Science, Tsukuba 305-0043, Japan \\ ${ }^{d}$ Department of Physics and Astronomy, University of North Carolina at Chapel Hill,
} Chapel Hill, NC 27599-3255, USA

* Corresponding author. Fax: +19199620480

Email:1cqin@unc.edu

\begin{abstract}
We have synthesized graphene by reducing carbon dioxide in magnesium and calcium metal flames. The as-prepared graphene has been used as conductive additive to improve the electrical conduction of activated carbon-based supercapacitor electrodes. The graphene/activated carbon composite electrode showed an outstanding specific capacitance of 220 and $180 \mathrm{~F} \mathrm{~g}^{-1}$ at a current density of $0.1 \mathrm{~A} \mathrm{~g}^{-1}$ in $6 \mathrm{M} \mathrm{KOH}$ electrolyte when using graphene obtained in magnesium flames and calcium flames, respectively.
\end{abstract}




\section{Introduction}

Supercapacitors based on the electrochemical double-layer capacitance are intermediates systems between electrochemical batteries and dielectric capacitors that utilize the double-layer formed at electrode/electrolyte interface to store and release energy [1,2]. Supercapacitors have been well recognized as an important energy storage device because of their pulse power supply, simple operation, long cycle life (> 100,000 cycles), and high dynamics of charge propagation $[3,4]$. With a high power capability and a relatively high energy density compared to conventional capacitors, supercapacitors have been widely employed in complementing or replacing batteries in many applications involving energy storage and management systems $[1,4]$.

At present, considerable efforts have been dedicated to exploring the high-performance carbon nanomaterials as electrodes of supercapacitors, owing to their excellent properties including stable electrochemical behavior, good cycle performance, and low cost [1]. On the other hand, as a unique carbon nanomaterial, the two-dimensional (2D) graphene with one-atom thickness is becoming a promising electrode material for fabricating high-performance supercapacitors because of its excellent electrical conductivity (>5000 S m$~^{-1}$ ), mechanical stability and flexibility, and exceptionally large specific surface area $\left(2630 \mathrm{~m}^{2} \mathrm{~g}^{-1}\right)$ and supercapacitors based on graphene and its composites have actually been developed recently [5-10].

Various experimental methods for scalable production of graphene have been developed in recent years. Of particular interest are methods including chemical 
reduction of exfoliated graphite oxide (graphene oxide), electrochemical exfoliation of graphite, chemical vapor deposition, and chemical reduction in metal flames [11-16].

In this Letter, we report the synthesis of graphene by reducing $\mathrm{CO}_{2}$ in magnesium and calcium flames and the structural and electrochemical characterization of the thus obtained graphene for supercapacitor applications. The graphene structure and physical properties were characterized by transmission electron microscopy (TEM), scanning electron microscopy (SEM), X-ray diffraction (XRD), and Raman spectroscopy. Electrochemical characterization used cyclic voltammetry (CV), electrochemical impedance spectroscopy (EIS), and galvanostatic charge-discharge (GC) to study and evaluate the electrochemical performance of the as-prepared graphene as conductive additive in assembled carbon supercapacitors.

\section{Experimental}

\subsection{Preparation of carbon materials}

Preparation of graphene was carried out using active metals $(\mathrm{Mg}$ and $\mathrm{Ca})$ and $\mathrm{CO}_{2}$ as carbon precursor. By burning $\mathrm{Mg}$ and $\mathrm{Ca}$ metals in a $\mathrm{CO}_{2}$ atmosphere, graphene was produced in the following reactions that took place during the process

$$
\begin{aligned}
& 2 \mathrm{Mg}(\mathrm{s})+\mathrm{CO}_{2}(\mathrm{~g})=2 \mathrm{MgO}(\mathrm{s})+\mathrm{C}(\mathrm{s}) \\
& 2 \mathrm{Mg}(\mathrm{s})+\mathrm{O}_{2}(\mathrm{~g})=2 \mathrm{MgO}(\mathrm{s})
\end{aligned}
$$

and

$$
\begin{aligned}
& 2 \mathrm{Ca}(\mathrm{s})+\mathrm{CO}_{2}(\mathrm{~g})=2 \mathrm{CaO}(\mathrm{s})+\mathrm{C}(\mathrm{s}) \\
& 2 \mathrm{Ca}(\mathrm{s})+\mathrm{O}_{2}(\mathrm{~g})=2 \mathrm{CaO}(\mathrm{s})
\end{aligned}
$$

After the explosive reactions, we collected the black graphene powders and 
transferred them to beaker filled with $10 \% \mathrm{HCl}$ to remove the metallic oxide and unreacted metal. The mixture was then vacuum filtered using polypropylene membrane with pore size of $0.45 \mu \mathrm{m}$ and washed with deionized water. The processed graphene material was finally obtained after the resultant residues were dried in vacuum overnight at room temperature.

\subsection{Structural characterization}

Scanning electron microscopy (SEM, Hitachi S4800) and transmission electron microscopy (TEM, Tecnai F20) were used to examine the morphology of all samples. X-Ray diffraction (XRD) was carried out using a D8 Advance (Bruker) diffractometer with $\mathrm{Cu} \mathrm{K \alpha}$ radiation $(\lambda=0.15418 \mathrm{~nm})$ to evaluate the crystallization of graphene. Raman spectroscopy (Thermo Scientific DXR) measurement using $532 \mathrm{~nm}$ laser was also performed to characterize the disorder and defects of graphene.

\subsection{Construction of supercapacitors and electrochemical characterization}

We used a two-electrode configuration to evaluate the electrochemical performance of the active electrode material in the constructed supercapacitors. The supercapacitor cells were assembled according to the reported method [3,17]. The electrode material consists of activated carbon matrix material, conductive additive, and polytetrafluoroethylene (PTFE) binder. The carbon paste was painted on current collectors. To construct a symmetric supercapacitor, two identical electrodes were separated by a glass fiber film and sandwiched in a stainless steel cell (CR2016).Electrochemical performance of the supercapacitor was examined by cyclic voltammetry $(\mathrm{CV})$, electrochemical impedance spectroscopy (EIS), and galvanostatic 
charge-discharge (GC) using a Zahner-zennium electrochemical workstation. The applied potential range for $\mathrm{CV}$ measurement was $-1-0 \mathrm{~V}$ with scan rates varying from 10 to $200 \mathrm{mV} \mathrm{s}^{-1}$. EIS measurement was carried out at an open circuit voltage with a sinusoidal signal of $5 \mathrm{mV}$ over the frequency range of $100 \mathrm{mHz}$ to $100 \mathrm{kHz}$. GC measurement at different constant current densities varying from 0.1 to $2.0 \mathrm{~A} \mathrm{~g}^{-1}$ was performed at charging voltage of $1 \mathrm{~V}$.

\section{Results and discussion}

\subsection{Structural characterization}

The obtained graphene material was fully analyzed by transmission electron microscopy (TEM) and scanning electron microscopy (SEM). Figure 1a shows a low magnification TEM image of the as-prepared graphene sample, in which the morphology of the graphene sheets is seen as superimposed squares and their sizes are typically between 50 and $200 \mathrm{~nm}$. The TEM image of graphene sheets shown in Figure $1 \mathrm{~b}$ reveals a typical sheet-like structure with fewer than five monolayers of graphene. Larger stacks of few-layer graphene sheets are shown in Figure 1c, where the graphene sheets are scrolled and entangled. The selected-area electron diffraction (SAED) pattern of graphene sheets is given as the inset in Figure 1c, where the (100) and (200) Bragg reflections from graphene are clearly shown while the (002) reflection is weak and diffused, attributing to the poor order in stacking and the few-layered structure. Figure 1d shows the TEM image of $\mathrm{MgO}$ crystals after the reactions completed. The $\mathrm{MgO}$ crystals exhibit cubic morphology with edge length of about $50 \mathrm{~nm}$. As observed in Figure 1a, the similar morphology of the graphene sheets 
indicates that the graphene was grown on the template $\mathrm{MgO}$ crystals $[12,18]$. From the SEM images of the as-prepared graphene shown in Figure 1e and $f$, the cubic morphology of graphene was also revealed with length of 50 to $200 \mathrm{~nm}$ in agreement with the TEM observations. Therefore, the $\mathrm{MgO}$ crystals served as templates for deposition of carbon and formation of graphene during the reactions.

Figure 2 shows the X-ray diffraction pattern of the graphene material prepared by using $\mathrm{Mg}$ as the reductant and $\mathrm{CO}_{2}$ as the oxidant. A relatively weak and broad graphitic (002) reflection at $2 \theta=26.4^{\circ}$, corresponding to an inter-layer spacing of about $0.34 \mathrm{~nm}$, is observed along with two additional peaks attributed largely to the $\{200\}$ and $\{220\}$ reflections of $\mathrm{MgO}$ appeared at $43.2^{\circ}$ and $62.6^{\circ}$, respectively. It should also be noted that the (100) reflection due to graphene coincides with the $\{200\}$ reflection of $\mathrm{MgO}$. The presence of the graphitic (002) peak in the XRD pattern indicates that multilayer graphene must have also been produced in the process.

Raman spectroscopy is a powerful technique for characterizing graphene material, because it can reveal fine structural and electronic information including disorder and defect structures in graphene $[19,20]$. We acquired Raman spectra using $532 \mathrm{~nm}$ radiation. In the Raman spectrum there are three main characteristic peaks, the $\mathrm{D}$ band arising from an in-plane breathing vibration mode, and the $\mathrm{G}$ band resulting from the doubly degenerate in-plane vibration mode, resulting in two peaks at about $\sim 1580$ and $\sim 1350 \mathrm{~cm}^{-1}$, respectively $[19,20]$. The other most prominent peak is the $2 \mathrm{D}$ band at $\sim 2700 \mathrm{~cm}^{-1}$, which has been used to distinguish monolayer, bilayer, and few-layer graphene on the basis of the position and shape of the 2D band [20]. 
Figure 3 shows the Raman spectrum of the graphene material prepared from the chemical reactions using magnesium metal and carbon dioxide as precursor. The $\mathrm{G}$ band is broadened and shifted upward to around $1582 \mathrm{~cm}^{-1}$, while the intensity of the $\mathrm{D}$ band at $1339 \mathrm{~cm}^{-1}$ showed a higher intensity. Though the observed Raman shift of the D band varies with the laser wavelength, the appearance of the D band is related to the structural disorder at defect sites [21]. The area ratio of the D band to $\mathrm{G}$ band is correlated with the disordered structure and the ratio will increase with increasing disorder [22]. As shown in Figure 3, the Raman spectrum has a much stronger D band with the $\mathrm{D}$ to $\mathrm{G}$ area ratio of 1.71 , attributing to a high concentration of defects and disorders at the edges. It should be noted that much lower concentrations of defects were observed in graphene samples produced by reducing $\mathrm{CO}_{2}$ in $\mathrm{Ca}$ flames or electrochemical exfoliation [14] in which the relative peak heights of the D and G bands are reversed. The peak position of the $2 \mathrm{D}$ band of the graphene material shown in Figure $3\left(2670 \mathrm{~cm}^{-1}\right)$ was slightly downshifted compared to those of the reported value for graphene $\left(2700 \mathrm{~cm}^{-1}\right)$ and graphite $\left(2687 \mathrm{~cm}^{-1}\right)$. As already reported in the literature, the monolayer graphene sheets will give rise to a single and sharp 2D peak located below $2700 \mathrm{~cm}^{-1}$, while the bilayer graphene sheets have a broader 2D peak at $2700 \mathrm{~cm}^{-1}$ and graphene sheets with more than five layers have a broad 2D peak with the positions significantly shifted to above $2700 \mathrm{~cm}^{-1}[19,20]$. Therefore, the Raman spectrum given in Figure 3 indicates that the graphene obtained in our experiment has typically fewer than five graphene layers.

\subsection{Electrochemical characterization}


The as-prepared graphene has been used as conductive additive in activated carbon electrodes and the supercapacitor performance was evaluated by cyclic voltammetry (CV), electrochemical impedance spectroscopy (EIS), and galvanostatic charge-discharge (GC). Figure $4 \mathrm{a}$ is the $\mathrm{CV}$ curves of the supercapacitor based on activated carbon (AC) electrodes incorporating with the as-prepared graphene produced in $\mathrm{Mg}$ flames $(\mathrm{G}(\mathrm{Mg}) / \mathrm{AC}$, red) and $\mathrm{Ca}$ flames $(\mathrm{G}(\mathrm{Ca}) / \mathrm{AC}$, black), respectively, in $6 \mathrm{M} \mathrm{KOH}$ aqueous electrolyte at the scan rate of $50 \mathrm{mV}^{-1}$. The characteristic rectangular shape of the $\mathrm{CV}$ loop indicates excellent charge propagation at the electrode-electrolyte interface according to the energy storage mechanism of electric double-layer capacitors (EDLC) [23,24]. Furthermore, the faradic pseudo-capacitance caused by functional groups on the electrode surface can be neglected because there were no apparent peaks due to faradaic oxidation-reduction current between -1 and $0 \mathrm{~V}$ [24]. Figure $4 \mathrm{~b}$ shows the typical charge and discharge curves $\mathrm{G}(\mathrm{Mg}) / \mathrm{AC}$ (red) and $\mathrm{G}(\mathrm{Ca}) / \mathrm{AC}$ (black), respectively, in $6 \mathrm{M} \mathrm{KOH}$ aqueous electrolyte at the current density of $0.1 \mathrm{Ag}^{-1}$. The linear profile of galvanostatic charge-discharge curves and their symmetric triangular shape indicate nearly ideal capacitive characteristics.

The specific capacitance of supercapacitor electrode is calculated from the galvanostatic discharge curve using the following equation [17]

$$
C_{2 E}^{\text {spec }}=\frac{4 I_{\text {cons }}}{M d V / d t}
$$

where $C_{2 E}^{s p e c}$ is the specific capacitance of the electrode, $I_{c o n s}$ is the constant current, $d V / d t$ is the slope of discharge curve obtained through linear fitting, and $M$ is the total 
weight of two symmetrical electrodes. At the constant current density of $0.1 \mathrm{Ag}^{-1}$, the specific capacitance of $\mathrm{G}(\mathrm{Mg}) / \mathrm{AC}$ and $\mathrm{G}(\mathrm{Ca}) \mathrm{AC}$ was $220 \mathrm{~F} \mathrm{~g}^{-1}$ and $185 \mathrm{~F} \mathrm{~g}^{-1}$, respectively. When the constant current density was increased to $2.0 \mathrm{~A} \mathrm{~g}^{-1}$, the specific capacitance of $186 \mathrm{~F} \mathrm{~g} \mathrm{~g}^{-1}$ and $147 \mathrm{~F} \mathrm{~g}^{-1}$ for $\mathrm{G}(\mathrm{Mg}) / \mathrm{AC}$ and $\mathrm{G}(\mathrm{Ca}) / \mathrm{AC}$, respectively. The apparent difference in specific capacitance of $\mathrm{G}(\mathrm{Mg}) / \mathrm{AC}$ and $\mathrm{G}(\mathrm{Ca}) / \mathrm{AC}$ is attributed to their structural differences. $\mathrm{G}(\mathrm{Ca}) / \mathrm{AC}$ is structurally closer to graphite - it contains more graphene layers and fewer defects. The rate performance of the supercapacitor electrode was also evaluated by galvanostatic charge-discharge under increased current density and the result is shown in Figure 4c. As shown in Figure $4 \mathrm{c}$, the $\mathrm{G}(\mathrm{Mg}) / \mathrm{AC}$ composite electrode preserved $85 \%$ of its specific capacitance when the charging current increased from 0.1 to $2.0 \mathrm{~A} \mathrm{~g} \mathrm{~g}^{-1}$, which is slightly higher than that of the $\mathrm{G}(\mathrm{Ca}) / \mathrm{AC}$ composite electrode. The fact that the specific capacitance will decrease with increasing current density is attributed to higher internal resistance and slower electrolyte diffusion in the electrode [25]. This is also confirmed by the Nyquist plots obtained from the EIS data given in Figure 4d. At low frequency, the straight line is nearly perpendicular to the real axis Z', indicating a pure capacitive behavior and that the electrolyte ions had completely diffused into the interior of the electrode material [3]. As the frequency increased, the influence of the electrode porosity was observed. When the frequency decreases, starting from very high frequency, the signal penetrates deeper and deeper into the porous structure of electrode, and then more and more electrode surface becomes approachable for ion adsorption [17]. There is also a domain in a small frequency range, where a straight 
line with a $45^{\circ}$ angle is observed, resulting from the diffusion of electrolyte ions (Warburg impedance) $[3,17,25]$. It is well known that the higher frequency the Warburg curve starts, the easier the electrolyte penetrates into the porous structure of the electrode. From the inset given in Figure $4 d$, it can be seen that the starting frequency of the Warburg curve for $\mathrm{G}(\mathrm{Mg}) / \mathrm{AC}$ electrode is $1332 \mathrm{~Hz}$, which is higher than that for $\mathrm{G}(\mathrm{Ca}) / \mathrm{AC}(674 \mathrm{~Hz})$. This result also confirms that the $(\mathrm{Mg}) / \mathrm{AC}$ electrode has better rate capability. Moreover, the transfer resistance $R_{t}$ of $G(M g) / A C$ electrode, which reflected the inter-granular contact resistance between AC particles and graphene sheets, is smaller, also implying easier diffusion of the electrolyte ions [17]. The semi-circle observed in the high frequency range where the equivalent series resistance (ESR) is obtained by extrapolating the straight line to intersect the real axis [25]. The ESR of $\mathrm{G}(\mathrm{Mg}) / \mathrm{AC}$ and $\mathrm{G}(\mathrm{Ca}) / \mathrm{AC}$ are 0.366 and $0.478 \Omega$, respectively, indicating a smaller intrinsic resistance of $\mathrm{G}(\mathrm{Mg}) / \mathrm{AC}$ and also a lower contact resistance at the interface between the active material and current collector [3].

\section{Conclusions}

We have synthesized and characterized graphene by the chemical reactions between $\mathrm{Mg} / \mathrm{Ca}$ metal and dry ice $\left(\mathrm{CO}_{2}\right)$ and improved the electrochemical performance of carbon supercapacitors when the graphene was used as conductive additive. High specific capacitance of $220 \mathrm{~F} \mathrm{~g}^{-1}$ in activated carbon electrode incorporating with the as-prepared graphene has been obtained at the constant current density of $0.1 \mathrm{~A} \mathrm{~g}^{-1}$, which is much higher than that of electrodes made of activated carbon incorporated with carbon blacks or graphite powders. 


\section{Acknowledgement}

J.T. wishes to thank the JST ALCA Program (Japan) for financial support. 


\section{REFERENCES}

[1] A.G. Pandolfo, A.F. Hollenkamp, J Power Sources 157 (2006) 11.

[2] L.L. Zhang, X. Zhao, Chem. Soc. Rev. 38 (2009) 2520.

[3] J. Gamby, P. Taberna, P. Simon, J. Fauvarque, M. Chesneau, J. Power Sources $101(2001) 109$.

[4] S. Bose, T. Kuila, A.K. Mishra, R. Rajasekar, N.H. Kim, J.H. Lee, J. Mater. Chem. 22 (2012) 767.

[5] M.D. Stoller, S. Park, Y. Zhu, J. An, R.S. Ruoff, Nano Lett. 8 (2008) 3498.

[6] S. Vivekchand, C.S. Rout, K. Subrahmanyam, A. Govindaraj, C. Rao, J. Chem. Sci. $120(2008) 9$.

[7] Q. Cheng, J. Tang, N. Shinya, L.-C. Qin, J. Power Sources 241 (2013) 423.

[8] Q. Cheng, J. Tang, J. Ma, H. Zhang, N. Shinya, L.-C. Qin, Phys. Chem. Chem. Phys. 13 (2011) 17615.

[9] Q. Cheng, J. Tang, J. Ma, H. Zhang, N. Shinya, L.-C. Qin, Carbon 49 (2011) 2917.

[10] K. Novoselov, A. Geim, S. Morozov, D. Jiang, Y. Zhang, S. Dubonos, I. Grigorieva, A. Firsov, Science 306 (2004) 666.

[11] Y. Hernandez, V. Nicolosi, M. Lotya, F.M. Blighe, Z. Sun, S. De, I.T. McGovern, B. Holland, M. Byrne, Y.K. Gunko, J.J. Boland, P. Niraj, G. Duesberg, S. Krishnamurthy, R. Goodhue, J. Hutchison, V. Scardaci, A.C. Ferrari, J.N. Coleman, Nat. Nanotechnol. 3 (2008) 563.

[12] G. Ning, Z. Fan, G. Wang, J. Gao, W. Qian, F. Wei, Chem. Commun. 47 (2011) 
5976.

[13] Y. Huang, J. Liang, Y. Chen, Small, 8 (2012) 1805.

[14] M. Zhou, J. Tang, Q. Cheng, G. Xu, P. Cui, L.-C. Qin, Chem. Phys. Lett. 572 (2013) 61.

[15] M. Zhou, T. Tian, X. Li, X. Sun, J. Zhang, Y. Chen, P. Cui, J. Tang, L.-C. Qin, Chem. Phys. Lett. 581 (2013) 64.

[16] A. Chakrabarti, J. Lu, J.C. Skrabutenas, T. Xu, Z. Xiao, J.A. Maguire, N.S. Hosmane, J. Mater. Chem. 21 (2011) 9491.

[17] C. Portet, P. Taberna, P. Simon, C. Laberty-Robert, Electrochim. Acta 49 (2004) 905.

[18] M.H. Rummeli, A. Bachmatiuk, A. Scott, F. Borrnert, J.H. Warner, V. Hoffman, J.-H. Lin, G. Cuniberti, B. Buchner, ACS Nano 4 (2010) 4206.

[19] A.C. Ferrari, Solid State Commun. 143 (2007) 47.

[20] A. Ferrari, J. Meyer, V. Scardaci, C. Casiraghi, M. Lazzeri, F. Mauri, S. Piscanec, D. Jiang, K. Novoselov, S. Roth, Phys. Rev. Lett. 97 (2006) 187401.

[21] Y. Wang, D.C. Alsmeyer, R.L. McCreery, Chem. Mater. 2 (1990) 557.

[22] A. Ferrari, J. Robertson, Phys. Rev. B 61 (2000) 14095.

[23] B. Conway, Electrochemical Supercapacitors: Scientific Fundamentals and Technological Applications. Kluwer Academic/Plenum: New York, 1999.

[24] J. Chen, W. Li, D. Wang, S. Yang, J. Wen, Z. Ren, Carbon 40 (2002) 1193.

[25] P. Taberna, P. Simon, J.-F. Fauvarque, J. Electrochem. Soc. 150 (2003) A292. 

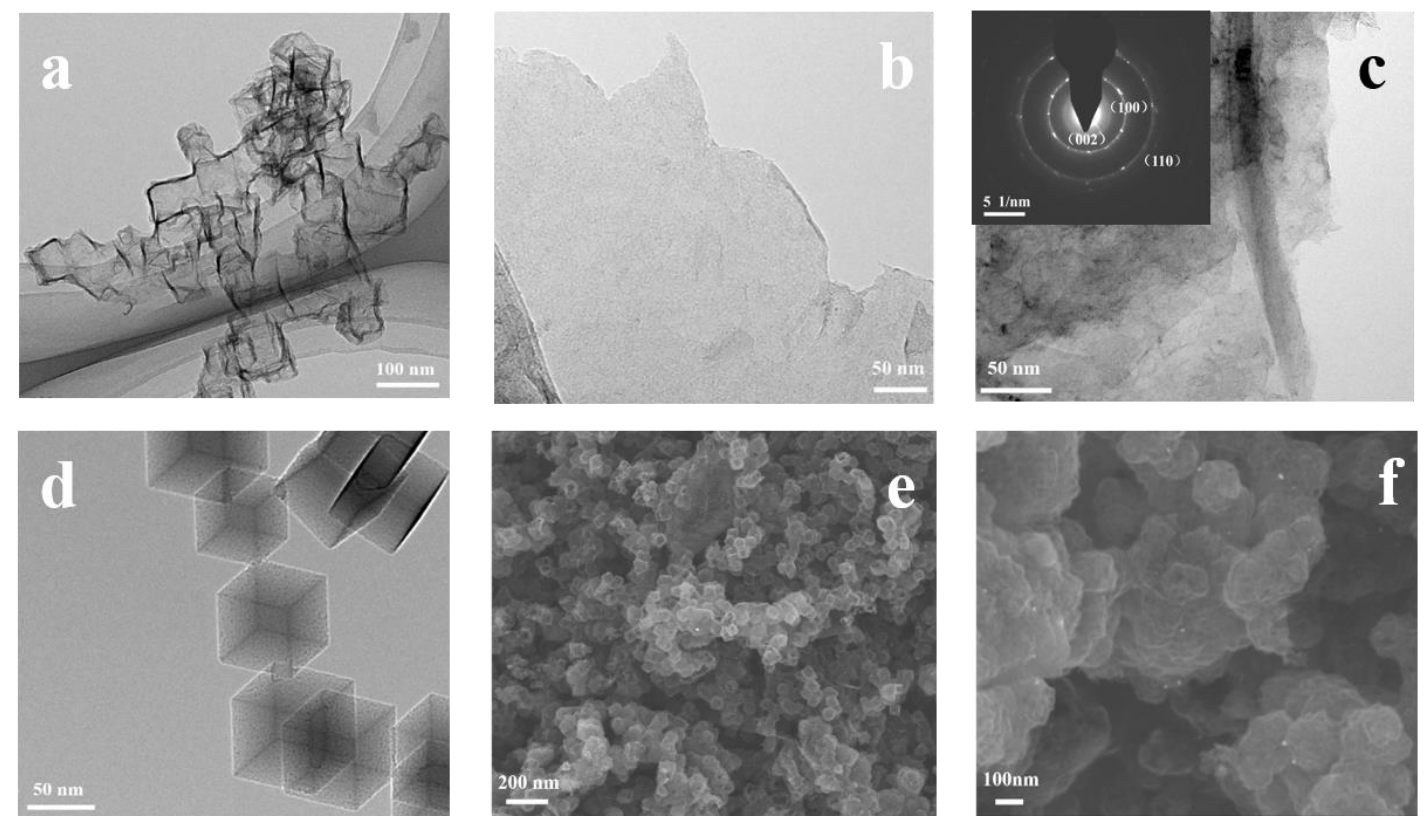

Figure 1 (a-c) TEM images of graphene prepared from chemical reactions in flames using magnesium metal and carbon dioxide as precursor. The inset in (c) is the SAED pattern, confirming the crystalline nature of the as-prepared graphene material; (d) TEM image of cubic $\mathrm{MgO}$ crystals; (e-f) SEM images of as-prepared graphene material. 


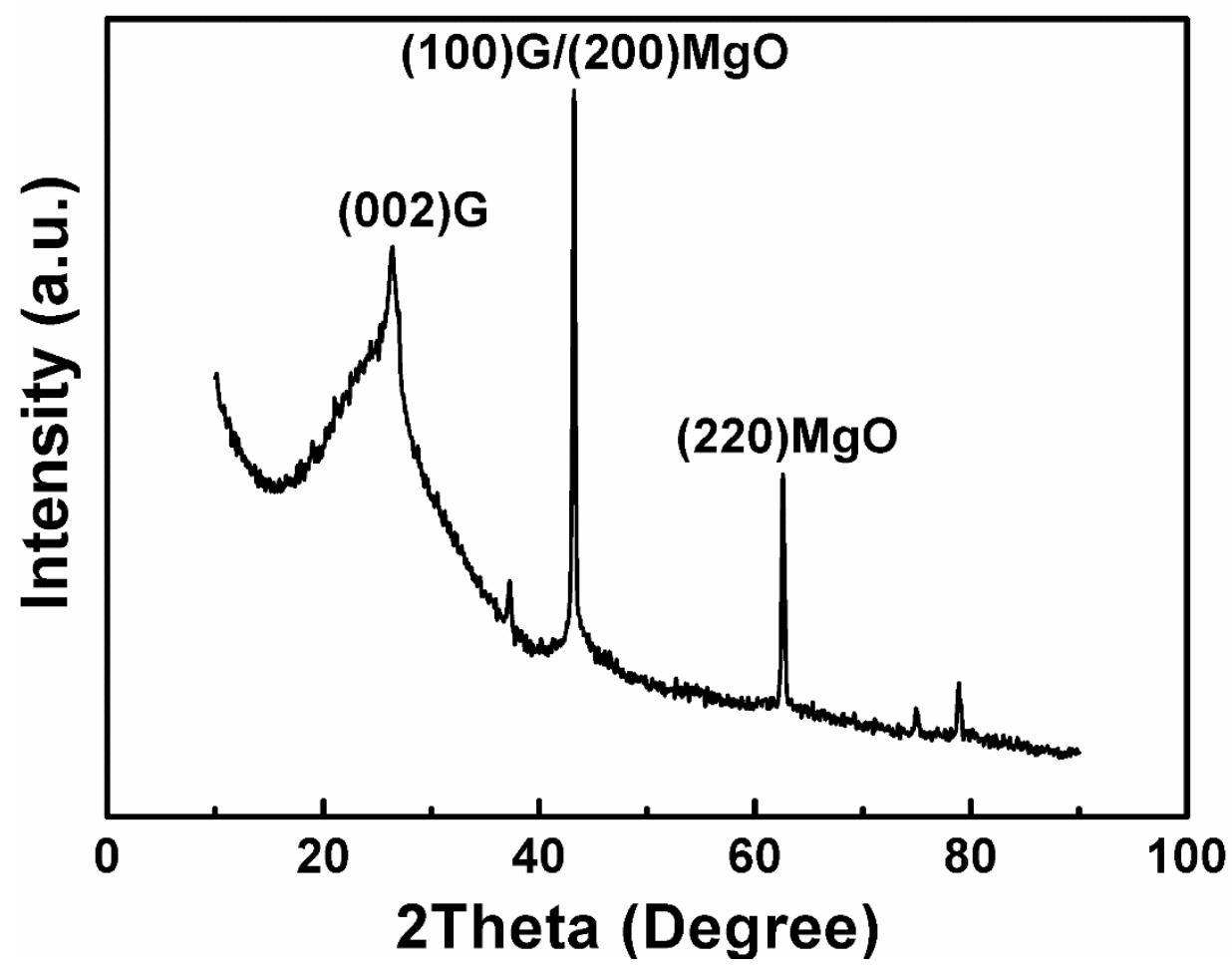

Figure $2 \mathrm{X}$-ray diffraction pattern of graphene using $\mathrm{Mg}$ as chemical reactants. The broadened (002) reflection is due to graphene and the sharp (200) and (220) reflections are due to $\mathrm{MgO}$ crystals. 


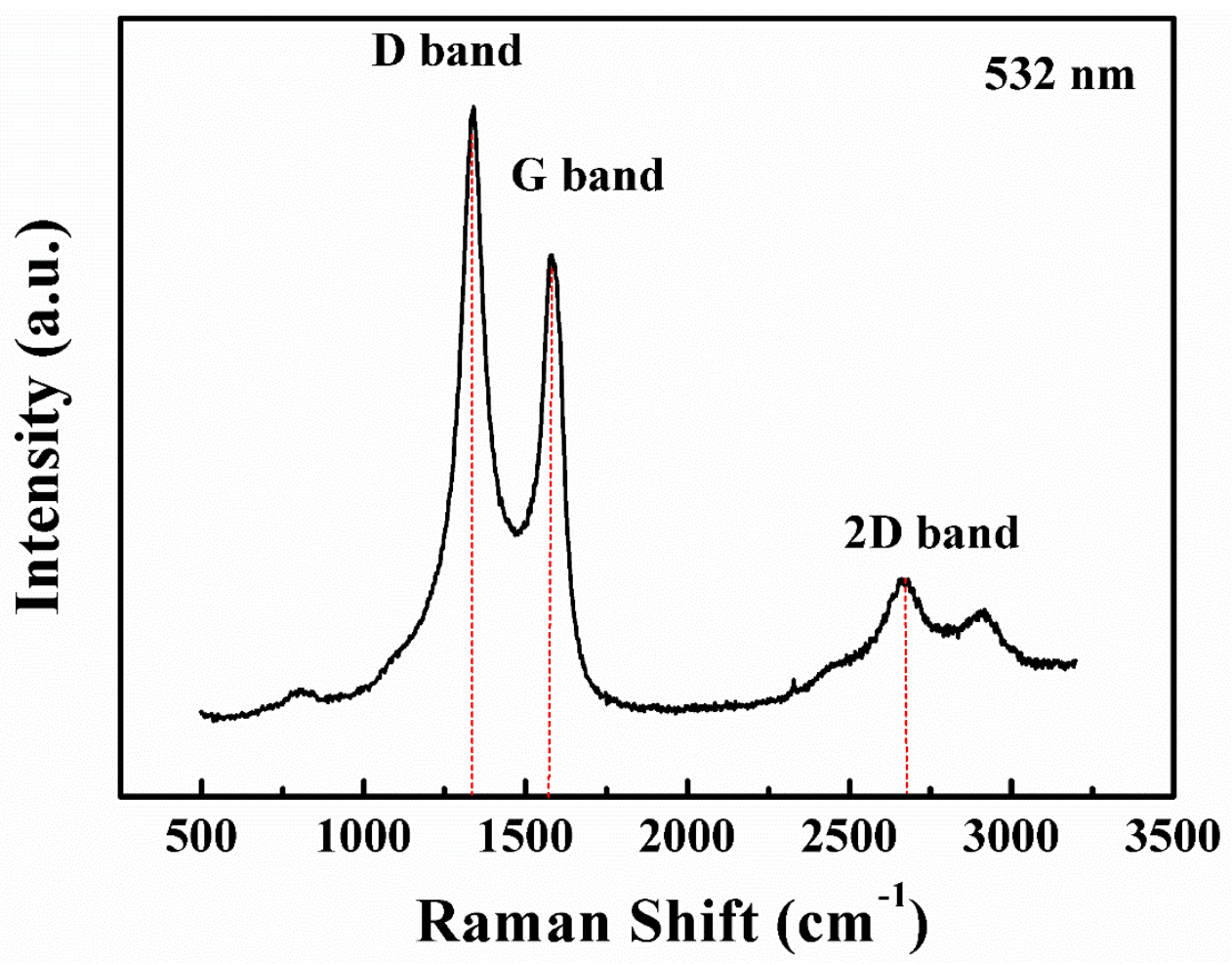

Figure 3 Raman spectra at $532 \mathrm{~nm}$ of as-prepared carbon material showing a D band at 1339 $\mathrm{cm}^{-1}$, a G band at $1582 \mathrm{~cm}^{-1}$, and a $2 \mathrm{D}$ band at $2670 \mathrm{~cm}^{-1}$. 

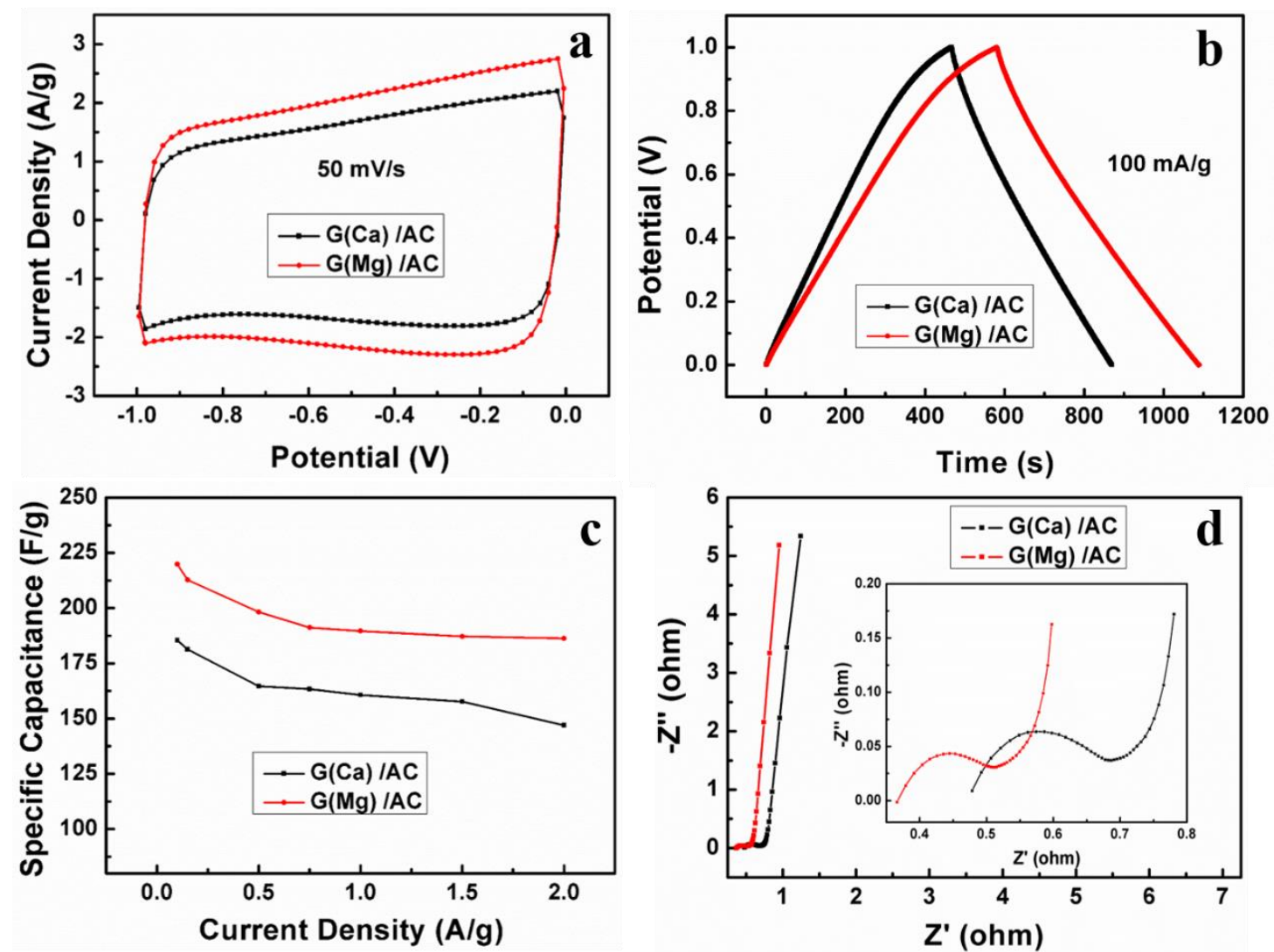

Figure 4 Electrochemical characterization of $\mathrm{G}(\mathrm{Mg}) / \mathrm{AC}$ and $\mathrm{G}(\mathrm{Ca}) / \mathrm{AC}$ supercapacitor electrode. (a) CV curves at scan rate of $50 \mathrm{mV} \mathrm{s}^{-1}$; (b) GC curves at constant current density of $100 \mathrm{~mA} \mathrm{~g}^{-1}$; (c) Specific capacitance obtained from GC curves at different current densities varying from 0.1 to $2.0 \mathrm{~A} \mathrm{~g}^{-1}$; (d) Nyquist plots of EIS data. 

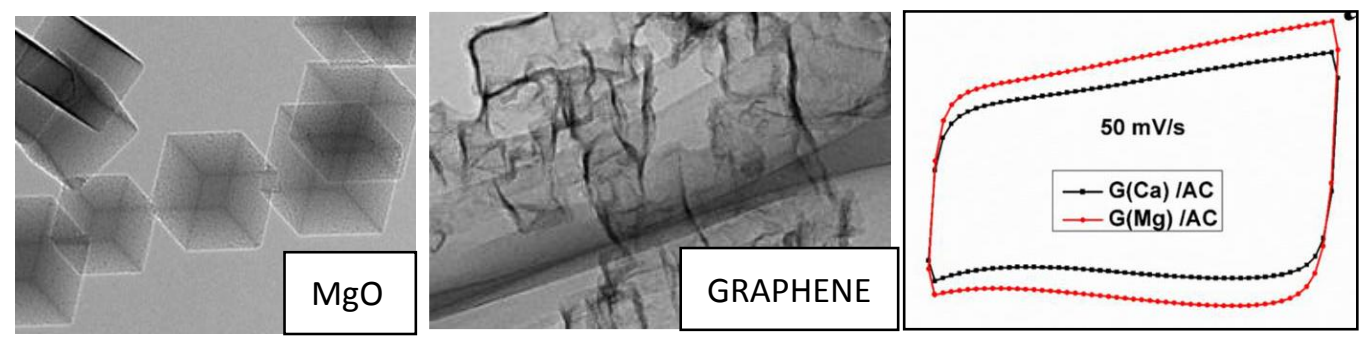